\title{
Community-acquired pneumonia in younger patients is an entity on its own
}

\author{
Benjamin Klapdor*, Santiago Ewig*, Mathias W. Pletz*, Gernot Rohde ", \\ Hartwig Schütte $^{+}$, Tom Schaberg ${ }^{\xi}$ and Tobias Welte $^{f}$ for the CAPNETZ study group
}

ABSTRACT: Community-acquired pneumonia (CAP) is now most frequent in elderly patients. CAP in the younger patient has attracted much less attention. Therefore, we compared patients with CAP aged 18 to $<65$ yrs with those aged $\geqslant 65$ yrs.

Data from the prospective multicentre Competence Network for Community Acquired Pneumonia Study Group (CAPNETZ) database were analysed for potential differences in baseline characteristics, comorbidities, clinical presentation, microbial investigations, aetiologies, antimicrobial treatment and outcomes.

Overall, 7,803 patients were studied. The proportion of younger patients (aged $<65$ yrs) was $52.3 \%$ (18 to $<30$ yrs $6.4 \%$; $<40$ yrs $17.1 \%$; $<50$ yrs $29.4 \%$ ). Comorbidity was present in only half of the younger patients (46.6\% versus $\mathbf{8 8 . 2} \%$ ). Fever and chest pain were more common. Most younger patients presented with mild CAP $(74.0 \%$ had a CURB-65 score of 0 (confusion of new onset, urea $>7 \mathrm{mmol} \cdot \mathrm{L}^{-1}$, respiratory rate of $\geqslant 30$ breaths $\cdot \mathrm{min}^{-1}$, blood pressure $<90 \mathrm{mmHg}$ or diastolic blood pressure $\leqslant 60 \mathrm{mmHg}$, age $\geqslant 65 \mathrm{yrs})$ ). Overall, Streptococcus pneumoniae and Mycoplasma pneumoniae were the most frequent pathogens in the younger patients. Short-term mortality was very low (1.7\% versus $8.2 \%$ ) and even lower in patients without comorbidity $(0.3 \%$ versus $2.4 \%)$. Longterm mortality was $3.2 \%$ versus $15.9 \%$, also lower in patients without comorbidity $(0.8 \%$ versus $6.1 \%)$.

Most of the differences found clearly arise after the fifth or within the middle of the sixth decade. CAP in the younger patient is a clinically distinct entity.

KEYWORDS: Community-acquired pneumonia, infections, outcomes

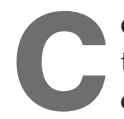
ommunity-acquired pneumonia (CAP) "in the elderly" as a subgroup has attracted considerable interest in the investigation of the disease during recent decades [1,2]. Additional classifications have emerged, such as CAP "in the very elderly" [3] and "nursing home-acquired pneumonia" [4-7] and, most recently, "healthcareassociated pneumonia" [8], indicating a considerable shift of interest to the elderly and disabled patients with pneumonia.

In fact, the epidemiology of CAP has undergone a remarkable change in Western countries. Along with increasing life expectancy and, as a consequence, comorbidity and dysfunction in the elderly, CAP is now essentially a condition of the elderly. Accordingly, in a large mandatory, nationwide quality-assurance programme that began in 2005 in Germany, $>80 \%$ of hospitalised cases with CAP were found to be aged $\geqslant 60$ yrs [9].

Controversy has arisen about the appropriate classification of patients with recent contact to healthcare institutions. Whereas there is no doubt that elderly and disabled patients have an increased mortality, it remains unproven that this excess mortality is truly directly related to different (multiresistant) pathogen patterns and inappropriate antimicrobial treatment $[7,10]$. We, therefore, advocated to focus on the prognostic implications of pneumonia in functionally disabled patients rather than on recommendations for broad-spectrum antimicrobial treatment [11]. other side of the coin, i.e. to what extent CAP in younger patients now differs from CAP in the elderly. The Competence Network for Community Acquired Pneumonia Study Group (CAPNETZ) database offers a unique opportunity to address this question. We, therefore, compared $\mathrm{CAP}$ in the elderly population aged $\geqslant 65$ yrs with that in the younger population. Because the frequently used cut-off of 65 yrs has not been validated, we performed comparisons across several decades (fifth,
However, much less attention has been paid to the

\section{AFFILIATIONS}

${ }^{*}$ Thoraxzentrum Ruhrgebiet, Dept of Respiratory and Infectious Diseases, EVK Herne and Augusta-KrankenAnstalt, Bochum,

"Division of Gastroenterology, Hepatology and Infectious Diseases, Jena University Hospital, Jena,

${ }^{+}$Medical Clinic, Infectious Diseases and Respiratory Medicine, Charité Berlin University, Berlin,

${ }^{\S}$ Diakoniekrankenhaus, Respiratory Clinic Unterstedt, Rotenburg an der Wümme,

${ }^{f}$ Dept of Pneumology, Hannover University, Hanover, Germany. "Dept of Respiratory Medicine, Maastricht University Medical Centre, Maastricht, The Netherlands.

CORRESPONDENCE

S. Ewig

Thoraxzentrum Ruhrgebiet

Kliniken für Pneumologie und Infektiologie

EVK Herne und Augusta-KrankenAnstalt Bochum

Bergstrasse 26

44791 Bochum

Germany

E-mail: ewig@augusta-bochum.de

Received:

June 282011

Accepted after revision:

Oct 062011

First published online:

Nov 162011 
fourth and third). We analysed potential differences in baseline characteristics, comorbidities, clinical presentation, microbial investigations, aetiologies, antimicrobial treatment and outcomes.

\section{METHODS}

\section{Patients}

Methodology of CAPNETZ has been reported elsewhere [12]. Briefly, in patients aged $\geqslant 18$ yrs, a pulmonary infiltrate diagnosed by chest radiograph and clinical symptoms consisting of fever, cough, purulent sputum or positive auscultation were included prospectively. Exclusion criteria were: age $<18 \mathrm{yrs}$; acquired or therapeutically induced immune deficiency; and active tuberculosis or a possible nosocomial genesis of infection (hospitalisation $<4$ weeks prior to infection). Cases were reported via a network of sentinel practices and hospitals to the participating local clinical centre.

The study was approved by the central and local ethics committees and written informed consent was obtained from all patients.

\section{Data collection}

Demographic, clinical and diagnostic data were recorded using standardised web-based data sheets. The study period comprised 90 months from January 2002 to June 2009, thus including almost eight autumn/winter seasons.

\section{Microbial investigation}

Methods applied have been described previously [12-16]. In short, samples obtained included sputum and/or other respiratory secretions, blood cultures, urinary antigen testing for Streptococcus pneumoniae and Legionella pneumophila serogroup 1, serology, and nasal and pharyngeal swabs. Investigations for viruses were performed only until July 2007. All samples were immediately processed in the participating local microbiological laboratories according to the German Quality Standards in Clinical Microbiology and Infectious Diseases [16].

Whereas the methodology of microbial investigation was standardised, microbial sampling was applied according to the decision of the attending physicians.

In order to limit possible bias due to incomplete sampling and limited diagnostic yield of microbial investigation, the frequencies of pathogens were reported using the following denominators: 1) total population; 2) cases with microbial sampling (including those techniques able to detect the pathogen in question); and 3) cases with a determined pathogen.

\section{CURB-65 score and mortality}

The CURB-65 score (confusion of new onset, urea $>7 \mathrm{mmol} \cdot \mathrm{L}^{-1}$, respiratory rate of $\geqslant 30$ breaths $\cdot \mathrm{min}^{-1}$, blood pressure $<90 \mathrm{mmHg}$ or diastolic blood pressure $\leqslant 60 \mathrm{mmHg}$, age $\geqslant 65 \mathrm{yrs}$ ) was determined in all patients. One point is given for each parameter present, which results in CURB-65 scores of $0-4$. For each patient, the CURB-65 score was calculated with patient data assessed at first presentation.

Short-term mortality was defined as death within 30 days and long-term mortality as death within 180 days of diagnosis.

\section{Statistical analysis}

Patients with CAP aged $\geqslant 65$ yrs were considered to represent the current standard group. Groups for comparison were formed by dividing the population four times using the thresholds of 18 to $<30$ yrs, $<40$ yrs, $<50$ yrs and $<65$ yrs.

Comparisons between groups were performed by means of the Chi-squared test for categorical variables and by means of the unpaired t-test for continuous variables (or by nonparametric Mann-Whitney U-test in case of not normally distributed data). All analyses were performed using SPSS software (SPSS 19.0; SPSS Inc., Chicago, IL, USA). All tests of significance were two-tailed, and $\alpha$ was set at 0.05 .

\section{RESULTS}

\section{Patient population}

Overall, 7,803 patients were included in our analysis. The 4,339 $(55.6 \%)$ male and $3,464(44.4 \%)$ female patients had a mean \pm SD age of $60.9 \pm 18.5$ yrs (range $18-101$ yrs). $68.8 \%(n=5,368)$ were hospitalised and $31.2 \%(n=2,435)$ were treated as outpatients.

At least one comorbidity was present in $65.1 \%(n=5,079)$ of patients and $8.2 \%(n=639)$ of patients were nursing home residents. $29 \%(n=2,290)$ of the patients were smokers. $91 \%$ of patients presented with cough, $58.0 \%$ had fever, $73.8 \%$ dyspnoea and $10.8 \%$ confusion. The distribution of CURB-65 risk classes (in patients with complete data sets) was as follows: CURB-65 score of 0 in $34.3 \%(n=2,677), 1-2$ in $50.6 \%$ $(n=3,945)$ and $3-4$ in $4.2 \%(n=328)$ of patients.

$3.4 \%(n=264)$ of patients required mechanical ventilation. Short-term mortality (within 30 days after diagnosis) was $4.4 \%$ $(\mathrm{n}=347)$ and long-term mortality (within 6 months after diagnosis) was $8.6 \%(n=668)$.

Data are summarised in detail across the predefined age decades in online supplementary table S1.

\section{Incidence of CAP in different decades}

The numbers of patients in each subgroup were: 18 to $<30 \mathrm{yrs}$, $503(6.4 \%) ;<40$ yrs, $1,338(17.1 \%) ;<50$ yrs, 2,293 (29.4\%), and $<65$ yrs, 4,083 (52.3\%). The corresponding hospitalisation rates were: $49.3 \%, 49.0 \%, 49.9 \%$ and $55.7 \%$, respectively.

\section{Comparison of younger and elderly patients aged $\geqslant 65$ yrs}

\section{Baseline characteristics}

Male sex accounted for $~ 50 \%$ of cases $(48.1 \%$ versus $53.5 \%$ ) and was not predominant in the young. Obesity (as defined by body mass index $\geqslant 30 \mathrm{~kg} \cdot \mathrm{m}^{-2}$ ) was less frequent in the younger patients. Younger patients were more frequently smokers ( $42.6 \%$ versus $16.1 \%)$. The rate of patients residing in nursing homes was very low in patients aged $<65$ yrs $(2.6 \%$ versus $14.4 \%$ ) (online supplementary table S1).

\section{Comorbidities}

Comorbidity constantly decreased with every decreasing decade; whereas it was present in $88.2 \%$ of those aged $\geqslant 65$ yrs, it was only $22.3 \%$ in the youngest patients aged 18 to $<30$ yrs. The largest increase was evident between the fifth and sixth decades (32.2\% and $46.6 \%$, respectively); however, it still was around half compared with the group aged $\geqslant 65$ yrs ( $46.6 \%$ versus $88.2 \%$ ). All comorbidities were more frequent in the group aged $\geqslant 65$ yrs except for chronic liver disease (online supplementary table S1). 


\section{Physical examination findings}

A positive auscultation finding, confusion, dyspnoea, tachypnoea and pleural effusion were all consistently less frequent in the younger decades. Fever ( $61.4 \%$ versus $54.2 \%$ ) and chest pain ( $49 \%$ versus $31.9 \%$ ) were more frequent in those aged $<65$ yrs (table 1 and online supplementary table S1).

\section{Laboratory investigations}

Anaemia was less frequent and lymphocyte count decreased with every decreasing decade; blood urea nitrogen increased with every increasing decade (online supplementary table S1).

\section{Gas exchange}

Hypoxia was less frequent in the younger patients and lowest in those aged 18 to $<30$ yrs ( $16.7 \%$ versus $36.0 \%$ ) (online supplementary table S1).

\section{Severity at presentation}

$44.3 \%$ of the younger patients were treated on an outpatients basis versus only $16.8 \%$ of those aged $\geqslant 65$ yrs. CURB- 65 risk class distribution was very similar across all younger decades (72-75\% risk class $1,24-28 \%$ risk class 2 and $<1 \%$ risk class 3 ). Mechanical ventilation was more frequent in those aged $\geqslant 65 \mathrm{yrs}(4.0 \%$ versus $2.8 \%)$. Time from symptoms until consultation was higher in the elderly decades (above the fourth decade) by $\sim 2$ days (online supplementary table S1).

\section{Microbial investigation}

Microbial work-up yielded a pathogen more frequently in younger patients $(30.8 \%$ versus $24.5 \%$; $<<0.001)$.

\section{Microbial aetiology}

S. pneumoniae was the most frequent pathogen in both age groups. Mycoplasma pneumoniae was the second most frequent in those aged $<65$ yrs $(8.4 \%$ of the total population, $9.7 \%$ of those with samples and $25.1 \%$ of those with pathogens determined). Influenzavirus A was less frequent in those aged $<65$ yrs $(1.5 \%$ versus $2.1 \%$ of the total population, $1.9 \%$ versus

\begin{tabular}{lccr} 
TABLE 1 & $\begin{array}{l}\text { Findings of physical examination at initial } \\
\text { presentation }\end{array}$ & \\
Variable & Age $<\mathbf{6 5}$ yrs & Age $\geqslant \mathbf{6 5}$ yrs & p-value \\
\hline Subjects $\mathbf{n}$ & 4083 & 3720 & \\
Positive auscultation & $2929(72.9)$ & $2936(80.3)$ & $<0.001$ \\
Cough & $3811(93.4)$ & $3285(88.8)$ & $<0.001$ \\
Purulent sputum & $2340(57.5)$ & $1985(53.7)$ & 0.001 \\
Fever & $2508(61.4)$ & $2015(54.2)$ & $<0.001$ \\
Dyspnoea & $2805(69.2)$ & $2950(80.2)$ & $<0.001$ \\
Confusion & $206(5.1)$ & $638(17.4)$ & $<0.001$ \\
Chest pain & $1967(49.0)$ & $1110(31.9)$ & $<0.001$ \\
Pleural effusion $^{\#}$ & $476(12.2)$ & $602(16.9)$ & $<0.001$ \\
Low blood pressure $^{\#}$ & $693(17.3)$ & $754(20.5)$ & $<0.001$ \\
Tachycardia $^{\text {T }}$ & $1189(29.6)$ & $1171(31.9)$ & 0.028 \\
Tachypnoea $^{+}$ & $294(8.0)$ & $430(12.7)$ & $<0.001$ \\
\hline
\end{tabular}

Data are presented as $n(\%)$, unless otherwise stated. ${ }^{*}$ : systolic blood pressure $<90 \mathrm{mmHg}$ or diastolic blood pressure $\leqslant 60 \mathrm{mmHg}^{\prime}{ }^{\prime}$ : heart rate $>100$ beats $\cdot \mathrm{min}^{-1} ;{ }^{+}$: respiratory rate $\geqslant 30$ breaths $\cdot \mathrm{min}^{-1}$.
$3.0 \%$ in those with samples and $4.6 \%$ versus $7.8 \%$ in those with determined pathogens). Enterobacteriaceae and Pseudomonas aeruginosa were exceedingly rare in those aged $<40 \mathrm{yrs}$ $(<2 \%)$ (table 2$)$.

In younger outpatients, M. pneumoniae was particularly frequent $(10.9 \%$ as compared with $6.5 \%$ in hospitalised younger patients) and was the most frequent pathogen across all age decades (online supplementary tables S2 and S3). In hospitalised patients, this was true for those aged $<40 \mathrm{yrs}$. In patients without comorbidity, M. pneumoniae was also the most frequent pathogen (online supplementary table S4).

Patients aged $<65$ yrs with any comorbidity less frequently had M. pneumoniae and more frequently had Enterobacteriaceae, $P$. aeruginosa and Staphylococcus aureus. However, absolute numbers of Enterobacteriaceae, P. aeruginosa and S. aureus were very low. The same was true for younger patients with chronic respiratory disease, with the exception that Haemophilus influenzae was also more frequent (online supplementary table S4).

\section{Antimicrobial treatment}

The younger patients more frequently had prior antimicrobial treatment $(\sim 6-12 \%)$ and monotherapy was more frequent in younger patients $(71.5 \%$ versus $66.6 \%)$. The younger patients had consistently received fewer $\beta$-lactams and more quinolones (62.5\% versus $81.3 \%$ and $28.2 \%$ versus $17.1 \%$, respectively). Duration of antimicrobial treatment was around 0.5 days shorter in those aged $<50$ yrs. A change in antimicrobial treatment was performed less frequently in younger patients $(27.0 \%$ versus $32.3 \%$ ), but still remained $>20 \%$ in those aged 18 to $<30 \mathrm{yrs}$ (table 3 and online supplementary tables S2 and S3).

In younger patients, the frequency of treatment changes was not increased in those without treatment active against $M$. pneumoniae $(\mathrm{n}=47(22.8 \%)$ versus $\mathrm{n}=16(16 \%) ; \mathrm{p}=0.17)$. Shortand long-term mortality in patients with $M$. pneumoniae was very low (one death within 180 days).

\section{Outcomes}

Short- and long-term mortality was $\leqslant 1 \%$ in patients aged $<50$ yrs. Short-term mortality was four-fold higher in the elderly (1.7\% versus $8.2 \%$ overall and $3.0 \%$ versus $9.9 \%$ in hospitalised patients). Short-term mortality was even lower in patients without comorbidity, but still eight-fold higher in the elderly ( $0.3 \%$ versus $2.4 \%$ ). Long-term mortality was $1.2 \%$ in those aged $<50$ yrs and was still low in those aged $<65$ yrs $(3.2 \%)$, but increased sharply in those aged $\geqslant 65$ yrs $(15.9 \%)$. Long-term mortality was also lower in patients without comorbidity, but was six-fold higher in the elderly ( $0.8 \%$ versus $6.1 \%$ ) (table 4 and online supplementary tables S2 and S3).

\section{Deaths in patients aged $<40$ yrs}

Overall, nine patients aged $<40$ yrs died. Seven of them were males and eight of them suffered from at least one comorbidity (one chronic respiratory disease, one congestive heart failure, one renal insufficiency and five other comorbidities). CURB-65 score was determined as 0 in three, as 1-2 in four and as 3-4 in one of them. All of the patients were hospitalised and five received mechanical ventilation. Pathogens were determined in four of these patients (one S. pneumoniae; one S. pneumoniae and S. aureus; 
TABLE 2 Aetiology of community-acquired pneumonia (CAP)

\begin{tabular}{|c|c|c|c|c|c|c|c|c|c|}
\hline \multirow[t]{2}{*}{ Variable } & \multicolumn{3}{|c|}{ Total population } & \multicolumn{3}{|c|}{ Cases with microbial sampling } & \multicolumn{3}{|c|}{ Cases with a pathogen determined } \\
\hline & CAP $<65$ yrs & CAP $\geqslant 65$ yrs & p-value & CAP $<65$ yrs & CAP $65 \geqslant y r s$ & p-value & CAP $<65$ yrs & CAP $\geqslant 65$ yrs & p-value \\
\hline $\begin{array}{l}\text { Streptococcus } \\
\text { pneumoniae }\end{array}$ & $375(9.2)$ & $330(8.9)$ & 0.063 & $375 / 3947(9.5)$ & $330 / 3444(9.6)$ & 0.906 & $375(28.0)$ & $330(33.2)$ & 0.007 \\
\hline $\begin{array}{l}\text { Mycoplasma } \\
\text { pneumoniae }\end{array}$ & $345(8.4)$ & $45(1.2)$ & 0.001 & $345 / 3560(9.7)$ & 45/2972 (1.5) & $<0.001$ & $345(25.1)$ & $45(4.5)$ & $<0.001$ \\
\hline $\begin{array}{c}\text { Haemophilus } \\
\text { influenzae }\end{array}$ & $86(2.1)$ & $53(1.4)$ & 0.023 & 86/3881 (2.2) & 53/3344 (1.6) & 0.052 & $86(6.4)$ & $53(5.3)$ & 0.269 \\
\hline Enterobacteria & $52(1.3)$ & $98(2.6)$ & 0.001 & $52 / 3881(1.3)$ & 98/3344 (2.9) & $<0.001$ & $52(3.9)$ & $98(9.9)$ & $<0.001$ \\
\hline $\begin{array}{c}\text { Pseudomonas } \\
\text { aeruginosa }\end{array}$ & $16(0.4)$ & $28(0.8)$ & 0.034 & $16 / 3881(0.4)$ & 28/3344 (0.8) & 0.021 & $16(1.2)$ & $28(2.8)$ & 0.004 \\
\hline $\begin{array}{l}\text { Staphylococcus } \\
\text { aureus }\end{array}$ & $51(1.2)$ & $38(1.0)$ & 0.344 & $51 / 3881$ (1.3) & $38 / 3344$ (1.1) & 0.495 & $51(3.8)$ & $38(3.8)$ & 0.989 \\
\hline Influenza A & $61(1.5)$ & $78(2.1)$ & 0.044 & $61 / 3158(1.9)$ & $78 / 2565$ (3.0) & 0.007 & $64(4.6)$ & $78(7.8)$ & 0.001 \\
\hline
\end{tabular}

Data are presented as $\mathrm{n}(\%)$ and $\mathrm{n} / \mathrm{N}(\%)$, unless otherwise stated. The aetiology is given according to three different denominators: 1) total population: number of pathogens per total population; 2) cases with microbial sampling: number of pathogens per patients having received at least one microbial investigation able to detect the pathogen in question; and 3) cases with a pathogen determined: number of pathogens per population with a pathogen established.

\section{TABLE 3 Initial antimicrobial treatment}

\begin{tabular}{|c|c|c|c|}
\hline \multirow[t]{2}{*}{ Variable } & \multicolumn{2}{|c|}{ Age } & \multirow[t]{2}{*}{ p-value } \\
\hline & $<65$ yrs & $\geqslant 65$ yrs & \\
\hline Subjects $\mathrm{n}$ & 4083 & 3720 & \\
\hline Prior antimicrobial therapy ${ }^{\#}$ & $1307(32.1)$ & $717(19.5)$ & $<0.001$ \\
\hline Initial antimicrobial therapy ${ }^{\pi}$ & $3996(98.0)$ & $3680(99.0)$ & $<0.001$ \\
\hline Monotherapy ${ }^{+}$ & 2856 (71.5) & 2450 (66.6) & $<0.001$ \\
\hline Combination therapy ${ }^{5}$ & $1120(28.0)$ & $1221(33.2)$ & $<0.001$ \\
\hline Duration of antimicrobial therapy & $\begin{array}{c}11.1 \pm 4.9 \\
(3779)\end{array}$ & $\begin{array}{c}11.1 \pm 4.6 \\
(3346)\end{array}$ & 0.982 \\
\hline Change in antimicrobial therapy & $1040(27.0)$ & 1115 (32.6) & $<0.001$ \\
\hline$\beta$-lactam antimicrobials & $2499(62.5)$ & 2990 (81.3) & $<0.001$ \\
\hline Penicillins & 1541 (34.6) & $1768(48.0)$ & $<0.001$ \\
\hline Cephalosporins & $936(23.4)$ & $1208(32.8)$ & $<0.001$ \\
\hline Carbapenems & $41(1.0)$ & $34(0.9)$ & 0.650 \\
\hline Macrolides & $1302(32.6)$ & $1155(31.4)$ & 0.262 \\
\hline Quinolones & $1128(28.2)$ & $631(17.1)$ & $<0.001$ \\
\hline Tetracylines & $38(1.0)$ & $22(0.6)$ & 0.079 \\
\hline Glycopeptides & $4(0.1)$ & $6(0.2)$ & 0.445 \\
\hline Lincosamides & $20(0.5)$ & $21(0.6)$ & 0.674 \\
\hline Ketolides & $69(1.7)$ & $23(0.6)$ & $<0.001$ \\
\hline Co-trimoxazole & $6(0.2)$ & $10(0.3)$ & 0.243 \\
\hline Aminoglycosides & $19(0.5)$ & $12(0.3)$ & 0.303 \\
\hline Other antimicrobials & $21(0.5)$ & $22(0.6)$ & 0.672 \\
\hline
\end{tabular}

Data are presented as $n(\%)$ or mean \pm SD $(n)$, unless otherwise stated. * : refers to antimicrobial treatment during the last 4 weeks. $\because$ : refers to the first antimicrobial therapy in hospital; ${ }^{+}$: any therapy with only one antimicrobial;

s: therapy with at least two antimicrobials administered in the hospital. one S. aureus; and one S. pneumoniae and influenza virus A). Five died within the first 30 days after admission.

\section{Ambulatory and hospitalised patients}

All calculations were repeated for ambulatory and hospitalised patients. With the exception that mechanical ventilation and treatment changes were not significantly more frequent in the elderly in hospitalised patients, the analysis revealed no significant differences to the results in the total population (online supplementary tables S2 and S3).

\section{DISCUSSION}

The most important differences in the younger population compared with the elderly in the present study are the following. 1) The incidence of CAP is low but still considerable $(17.1 \%$ of cases in those aged $<40 \mathrm{yrs}) ; 2)$ younger patients are free of comorbidity in more than half of cases; 3 ) most cases present with mild-to-moderate severity, nevertheless, hospitalisation rates are still high $(55.7 \%) ; 4)$ fever, chest pain and lymphocytosis are more frequently present; 5) S. pneumoniae and $M$. pneumoniae are the most frequent pathogens in younger patients overall, with M. pneumoniae being the most frequent in younger outpatients and those without comorbidities; 6) differences in treatment include more frequent antimicrobial pre-treatment, monotherapy, treatment with quinolones instead of $\beta$-lactams, fewer treatment changes and shorter treatment duration; and 7) short- and long-term mortality is very low, and long-term mortality is also low (3.2\%).

Our methodological approach using different decades as cut-offs allowed us to identify consistent age-related differences in CAP and obviated the potential biases of $\alpha$-inflation and possibly significant but not intrinsically age-related differences. The sum 


\begin{tabular}{|c|c|c|c|c|}
\hline TABLE 4 & $\begin{array}{l}\text { Overal } \\
\text { patien }\end{array}$ & $\begin{array}{l}\text { in hosp } \\
\text { comorb }\end{array}$ & ed patien & and in \\
\hline \multirow{2}{*}{\multicolumn{2}{|c|}{ Variable }} & \multicolumn{2}{|c|}{ Age } & \multirow[t]{2}{*}{ p-value } \\
\hline & & $<65$ yrs & $\geqslant 65$ yrs & \\
\hline Subjects $n$ & & 4083 & 3720 & \\
\hline \multicolumn{5}{|c|}{ Outcome overall } \\
\hline Died withir & 30 days & $65(1.7)$ & $282(8.2)$ & $<0.001$ \\
\hline Died withir & 80 days & $124(3.2)$ & $544(15.9)$ & $<0.001$ \\
\hline \multicolumn{5}{|c|}{$\begin{array}{l}\text { Outcome in hospitalised } \\
\text { patients }\end{array}$} \\
\hline Died withir & 30 days & $64(3.0)$ & $278(9.9)$ & $<0.001$ \\
\hline Died withir & 80 days & $114(5.4)$ & $528(18.8)$ & $<0.001$ \\
\hline \multicolumn{5}{|c|}{$\begin{array}{l}\text { Outcome in patients without } \\
\text { comorbidity }\end{array}$} \\
\hline Died withir & 30 days & $6(0.3)$ & $10(2.4)$ & $<0.001$ \\
\hline Died withir & 80 days & $17(0.8)$ & $25(6.1)$ & $<0.001$ \\
\hline
\end{tabular}

Data are presented as $n(\%)$, unless otherwise stated.

of all the differences allowed characterisation of a clinically relevant entity of CAP in the younger patients that was clearly different from that in those aged $\geqslant 65$ yrs.

The incidence of CAP in the decades $<65$ yrs was low but still remarkable. Our data are in line with the incidence rates reported recently in hospitalised patients in Germany. Overall, incidence ranged between 0.33 and 1.34 per 1,000 persons per year and comprised 35,946 cases, corresponding to $19.3 \%$ of all cases aged $<60$ yrs [9].

Several differences found were in the expected range, but nevertheless result in a pattern discriminative enough to establish an entity on its own. The typical younger patient had no comorbidity, presented with fever and chest pain, and had mild pneumonia. Accordingly, a change in antimicrobial treatment was less frequent and mean treatment duration was shorter. In fact, the difference in comorbidity rates is impressive $(\sim 22.3 \%$ in those aged 18 to $<30 \mathrm{yrs}$ versus $88.2 \%$ in those aged $\geqslant 65 \mathrm{yrs}$ ). Mortality is exceedingly low and increases significantly only in the ages $\geqslant 65 \mathrm{yrs}$. Interestingly, short- and long-term mortality in those without comorbidity was lower in both groups, but still higher in the elderly (eight- and six-fold, respectively). Whereas most deaths seem to be related to comorbidity, age may cause a small but relevant increase in pneumonia-associated death.

M. pneumoniae has long been recognised to be more frequent in younger patients [17-20]. Our data confirm this finding. In fact, in our study, M. pneumoniae was the second most frequent pathogen, regardless of the denominator used for calculating rates. $M$. pneumoniae may override the frequency of $S$. pneumoniae in younger outpatients and those without comorbidity. As many patients were treated with a regimen active against this pathogen, it is not possible to decide from our data whether there is a need to cover this pathogen empirically. However, a comparison of the groups treated with regimens including active and inactive drugs did not show a significant difference in treatment changes. Mortality was minimal. Regular coverage for M. pneumoniae is probably not mandatory in terms of mortality $[14,18,19]$. Clearly,
Enterobacteriaceae and P. aeruginosa are virtually absent and do not need to be considered regularly. As expected, seasonal influenzavirus A was more frequent in the elderly; with the emergence of novel H1N1 influenza, younger patients are more frequently affected [21]. These general patterns were not essentially different in younger patients with any comorbidity or chronic respiratory disease. Nevertheless, a careful assessment of individual risk factors, such as comorbidity, remains important in order to identify patients at increased risk of unusual pathogens at a younger age.

We also analysed nine patients aged $<40$ yrs who died. Of these, a pathogen was isolated in four, three had S. pneumoniae and two dual infection. These cases illustrate that empirical antimicrobial coverage should always include $S$. pneumonia and consider initial dual coverage in all patients at higher risk and presenting with high severity. We were not able to analyse the performance of management in these patients from our database. Scarce data published to date in this younger population dying from pneumonia revealed that management was not ideal [22]. An aggressive approach to reduce mortality from CAP seems mandatory; however, the policies to achieve this goal need to be determined in the near future [23]. Obviously, the specific challenge in younger patients is to detect the low number of cases with severe pneumonia who are at a high risk of death.

Two important age-related differences in management attitudes deserve comment. First, younger patients were hospitalised in nearly $50 \%$ of cases, despite the fact that around $75 \%$ of patients had a CURB-65 score of 0 . This was equally true for the youngest aged 18 to $<30 \mathrm{yrs}$. Secondly, we found that younger patients more frequently received quinolones. This practice is not in line with European and German guidelines [24, 25]. The reasons behind this attitude are unclear. Management policies in the young need to be investigated in different future populations in order to identify (and possibly question) local attitudes.

Long-term mortality has only recently been recognised as an important challenge in the management of patients after CAP [26, 27]. According to our data, it begins to increase in those aged $>50$ yrs. It is nearly two-fold higher than short-term mortality, and the same is true for patients without comorbidities. Although mortality numbers are low, these trends support the need for an increased attention to the reasons for long-term mortality of CAP and possible intervention strategies in the younger patient.

The main strengths of our study are the large number of patients investigated across 10 clinical centres and including eight autumn/winter seasons. To the best of our knowledge, patients with CAP aged $<65$ yrs have never been systematically investigated and have not been compared with those aged $\geqslant 65$ yrs. We cannot exclude undercounting, particularly of outpatients, as we did not record the total number of eligible cases with CAP. However, a higher inclusion rate of outpatients would have increased patients with mild pneumonia and, therefore, may even have augmented the differences described. One limitation of our study is the relatively low number of patients with severe CAP. The incidence of younger patients with severe CAP may therefore be underestimated. However, the main patterns of $\mathrm{CAP}$ in younger patients, as evident from these data, do not seem to be affected. Another limitation is that all data were captured prior to the emergence of novel H1N1 influenzavirus, which is now known to have a considerable impact on the epidemiology of CAP in younger patients. 
In conclusion, we describe a clinically distinct entity of CAP in the younger population. It is a condition occurring in subjects with far less comorbidity, and presenting in a clinically more classical manner, with fever, chest pain and less severe symptoms. Shortterm mortality is exceedingly low. Most of the differences found clearly arise after the fifth or within the middle of the sixth decade. The cut-off age of $65 \mathrm{yrs}$ seems to be a reasonable threshold at which to differentiate CAP in younger patients; however, the optimal threshold is not yet known. M. pneumoniae is a more frequent pathogen in the younger patient, particularly in outpatients and patients without comorbidity. The therapeutic implications of this finding are probably limited due to the mild course of the disease. Long-term mortality is already a concern in those aged $>50 \mathrm{yrs}$, regardless of comorbidity. We argue that these findings support our tentative concept of adult CAP consisting of two different entities: CAP in the younger aged $<65$ yrs and CAP in the elderly aged $\geqslant 65 \mathrm{yrs}$, with the latter group being separated further with regard to functional status into two subgroups with dramatically different outcomes [11, $28,29]$. Clearly, further studies are needed to validate these data outside of Germany. In addition, concepts are constantly being challenged by new developments, such as novel H1N1 influenzavirus-associated pneumonia, and should, therefore, remain attentive for new trends.

\section{STATEMENT OF INTEREST}

None declared.

\section{REFERENCES}

1 Venkatesan P, Gladman J, Macfarlane JT, et al. A hospital study of community acquired pneumonia in the elderly. Thorax 1990; 45: 254-259.

2 Carr B, Walsh JB, Coakley D, et al. Prospective hospital study of community acquired lower respiratory tract infection in the elderly. Respir Med 1991; 85: 185-187.

3 Fernández-Sabé N, Carratalà J, Rosón B, et al. Communityacquired pneumonia in very elderly patients: causative organisms, clinical characteristics, and outcomes. Medicine 2003; 82: 159-169.

4 Garb JL, Brown RB, Garb JR, et al. Differences in etiology of pneumonias in nursing home and community patients. JAMA 1978; 240: 2169-2172.

5 Marrie TJ, Durant H, Kwan C. Nursing home-acquired pneumonia. A case-control study. J Am Geriatr Soc 1986; 34: 697-702.

6 Lim WS, Macfarlane JT. A prospective comparison of nursing home acquired pneumonia with community acquired pneumonia. Eur Respir J 2001; 18: 362-368.

7 Polverino E, Dambrava P, Cillóniz C, et al. Nursing home-acquired pneumonia: a 10 year single-centre experience. Thorax. 2010; 65: 354-359.

8 Kollef MH, Shorr A, Tabak YP, et al. Epidemiology and outcomes of health-care-associated pneumonia: results from a large US database of culture-positive pneumonia. Chest 2005; 128: 3854-3862.

9 Ewig S, Birkner N, Strauss R, et al. New perspectives on community-acquired pneumonia in 388406 patients. Results from a nationwide mandatory performance measurement programme in healthcare quality. Thorax 2009; 64: 1062-1069.

10 Carratalà J, Mykietiuk A, Fernández-Sabé N, et al. Health careassociated pneumonia requiring hospital admission: epidemiology, antibiotic therapy, and clinical outcomes. Arch Intern Med 2007; 167: 1393-1399.

11 Ewig S, Welte T, Chastre J, et al. Rethinking the concepts of community-acquired and health-care-associated pneumonia. Lancet Infect Dis 2010; 10: 279-287.
12 Welte T, Suttorp N, Marre R. CAPNETZ-community-acquired pneumonia competence network. Infection 2004; 32: 234-238.

13 von Baum H, Ewig S, Marre R, et al. Competence Network for Community Acquired Pneumonia Study Group. Communityacquired Legionella pneumonia: new insights from the German competence network for community acquired pneumonia. Clin Infect Dis 2008; 46: 1356-1364.

14 von Baum H, Welte T, Marre R, et al. Mycoplasma pneumoniae pneumonia revisited within the German Competence Network for Community-Acquired Pneumonia (CAPNETZ). BMC Infect Dis 2009; 9: 62.

15 von Baum H, Schweiger B, Welte T, et al. CAPNETZ Study Group. How deadly is seasonal influenza-associated pneumonia? The German Competence Network for Community-Acquired Pneumonia. Eur Respir J 2011; 37: 1151-1157.

16 Mauch H, Lütticken R, Gatermann S, eds. MiQ 7 und 8. Infektionen der tiefen Atemwege. Teil I und II. Qualitätsstandards in der mikrobiologisch-infektiologischen Diagnostik [Infection of the Deep Airways. Part I and II. Quality Standards in the Microbiological Diagnosis of Infectious Diseases]. Jena, Gustav-Fischer Verlag, 1999.

17 Garibaldi RA. Epidemiology of community-acquired respiratory tract infections in adults. Incidence, etiology, and impact. Am J Med 1985; 78: 32-37.

18 Marrie TJ. Mycoplasma pneumoniae pneumonia requiring hospitalization, with emphasis on infection in the elderly. Arch Intern Med 1993; 153: 488-494.

19 Lieberman D, Schlaeffer F, Lieberman D, et al. Mycoplasma pneumoniae community-acquired pneumonia: a review of 101 hospitalized adult patients. Respiration 1996; 63: 261-266.

20 Ruiz M, Ewig S, Marcos MA, et al. Etiology of communityacquired pneumonia: impact of age, comorbidity, and severity. Am J Respir Crit Care Med 1999; 160: 397-405.

21 Jain S, Kamimoto L, Bramley AM, et al. 2009 Pandemic Influenza A (H1N1) Virus Hospitalizations Investigation Team. Hospitalized patients with 2009 H1N1 influenza in the United States, AprilJune 2009. N Engl J Med 2009; 361: 1935-1944.

22 Tang CM, Macfarlane JT. Early management of younger adults dying of community acquired pneumonia. Respir Med 1993; 87: 289-294.

23 Ewig S, Torres A. Pneumonia as an emergency: time for an aggressive approach to lower mortality. Eur Respir J 2011; 38 : 253-260.

24 Woodhead M, Blasi F, Ewig S, et al. Guidelines for the management of adult lower respiratory tract infections. Eur Respir J 2005; 26: 1138-1180.

25 Höffken G, Lorenz J, Kern W, et al. Guidelines of the Paul-EhrlichSociety of Chemotherapy, the German Respiratory Diseases Society, the German Infectious Diseases Society and of the Competence Network CAPNETZ for the Management of Lower Respiratory Tract Infections and Community-acquired Pneumonia. Pneumologie 2010; 64: 149-154.

26 Johnstone J, Eurich DT, Majumdar SR, et al. Long-term morbidity and mortality after hospitalization with community-acquired pneumonia: a population-based cohort study. Medicine (Baltimore) 2008; 87: 329-334.

27 Yende S, D'Angelo G, Kellum JA, et al. GenIMS Investigators. Inflammatory markers at hospital discharge predict subsequent mortality after pneumonia and sepsis. Am J Respir Crit Care Med 2008; 177: 1242-1247.

28 van der Steen JT, Ooms ME, Mehr DR, et al. Severe dementia and adverse outcomes of nursing home-acquired pneumonia: evidence for mediation by functional and pathophysiological decline. J Am Geriatr Soc 2002; 50: 439-448.

29 Torres $\mathrm{OH}, \mathrm{Muñoz} \mathrm{J}$, Ruiz D, et al. Outcome predictors of pneumonia in elderly patients: importance of functional assessment. J Am Geriatr Soc 2004; 52: 1603-1609. 